\begin{abstract}
УДК 378:303.447.3
ТРАДИЦИОННАЯ ВУЗОВСКАЯ ЛЕКЦИЯ В УСЛОВИЯХ КРЕДИТНОЙ ТЕХНОЛОГИИ: РЕЗУЛЬТАТЫ ЭКСПЕРИМЕНТАЛЬНОГО ИССЛЕДОВАНИЯ

Тасыбаева Ш.Б., Пономаренко Е.В., Серикулы Ж., Кумисбеков С.А., Хамитова Б.М.

РГП на ПХВ «Южно-Казахстанский государственный университет им. М. Ауэзова», Шылкент, e-mail: tasybaeva_s@mail.ru

В статье представлены результаты экспериментального исследования эффективности лекции в условиях кредитной технологии. Лекция является традиционной формой обучения в высшей школе. Особенности кредитной технологии заключаются в сокращении аудиторного времени и увеличении времени на самостоятельную работу студентов. Лекция должна соответствовать этим требованиям. Но анализ литературы показал отсутствие исследований по этой теме. В статье описаны особенности лекции на основе компетентностного подхода и кредитной технологии. Предлагается система оценки и диагностики, описаны содержание и этапы эксперимента. Применены такие методы исследования, как анализ литературы, сопоставление, классификация, прогнозирование, наблюдение, анкетирование, беседа, эксперимент, систематизация, обобщение. Сделан вывод о том, что традиционная форма проведения лекции не соответствует требованиям кредитной технологии. Сделано прогнозное предположение о дальнейших этапах исследования.
\end{abstract}

Ключевые слова: высшая школа, обучение, кредитная технология, лекция

\title{
TRADITIONAL HIGHER EDUCATION LECTURE IN THE CONDITIONS OF CREDIT TECHNOLOGY: THE RESULTS OF EXPERIMENTAL STUDIES
}

Tasybaeva Sh.B., Ponomarenko E.V., Serikuly Zh., Kumisbekov S.A., Khamitova B.M.

M. Auezov South Kazakhstan State University, Shymkent, e-mail: tasybaeva_s@mail.ru

\begin{abstract}
The article presents the results of an experimental study of the effectiveness of a lecture in the context of credit technology. Lecture is a traditional form of education in higher education. Features of credit technology consist in reducing the classroom time and increasing the time for independent work of students. The lecture should meet these requirements. But an analysis of the literature showed a lack of research on this topic. The article describes the features of the lecture based on the competence approach and credit technology. The system of evaluation and diagnostics is offered, the content and stages of the experiment are described. Such methods of research as literature analysis, comparison, classification, forecasting, observation, questioning, conversation, experiment, systematization, generalization are used. It is concluded that the traditional form of the lecture does not meet the requirements of credit technology. A predictive assumption is made about the further stages of the study.
\end{abstract}

Keywords: high school, teaching, credit technology, lecture

Придать вузовской лекции современный вид непросто. В традиционном понимании лекция - это систематизированное изложение учебного материала в последовательной, доступной форме [1-3]. Содержание лекции, методика ее проведения обусловлены целым рядом факторов. На лекции, по определению, должна быть успешно реализована совокупность взаимосвязанных целей и задач - передача и анализ фундаментальных и прикладных знаний, формирование прочной основы для последующего усвоения материала и вовлечение обучающихся в самостоятельную и исследовательскую работу, формирование широкого спектра универсальных и предметных компетенций. Именно во время лекции в традиционном понимании у педагога есть уникальная возможность заложить основы научных знаний, познакомить обучающихся с методологией научного поиска, выстроить логичную, стройную систему научного знания.

Современная высшая школа работает на основе методологии компетентностного подхода [4-7]. В связи с осо- 
бенностями кредитной технологии, такими как, например, сокращение аудиторного времени и увеличение доли самостоятельной работы обучающихся, лекция претерпевает существенные изменения. Как показывает опыт работы в вузе, традиционный подход к проведению лекции не всегда приводит к получению ожидаемых результатов [8]. Однако научно-педагогических исследований, главным результатом которых было бы выделение, обоснование и классификация особенностей лекции для современной высшей школы, работающей в условиях кредитной технологии, авторами не выявлено. Налицо актуальность исследования, посвященного устранению противоречия между потребностью вооружения педагогов высшей школы научно-практическими и методическими знаниями для проведения лекций в условиях кредитной технологии обучения и реальным положением дидактики высшей школы. На первом этапе следует провести теоретическое и экспериментальное исследование эффективности вузовской лекции в условиях кредитной технологии.

\section{Цель исследования}

Выявить отличительные особенности лекции в высшей школе с учетом методологии компетентностного подхода и правил кредитной технологии, разработать систему оценки и диагностики, экспериментально проверить эффективность вузовской лекции в условиях кредитной технологии.

\section{Методы исследования}

Анализ литературы, сопоставление, классификация, прогнозирование, наблюдение, анкетирование, беседа, эксперимент, систематизация, обобщение, формулирование выводов.

\section{Результаты исследования и их обсуждение}

Перед высшими учебными заведениями поставлена задача подготовки выпускников, способных быстро адаптироваться к меняющимся жизненным и профессиональным ситуациям, самостоятельно приобретать знания в течение всей жизни, критически и творчески мыслить, генерировать идеи, говорить на нескольких языках, работать в группе, вступать в контакт со специалистами смежных областей [1-4] и многое другое. В основе модернизации высшей школы - компетентностный подход, метод анализа и совершенствования образовательных систем в плане их соответствия цели и задачам формирования компетенций.

В литературе встречаем утверждение о том, что компетенция как характеристика индивидуальных интеллектуальных ресурсов предполагает высокий уровень разных типов знаний, определенные качества мышления, мотивацию, готовность принимать решения в соответствующих ситуациях, сформированную систему ценностей [2-5] и т.д. Однако тот факт, что системообразущим основанием компетентности является личность, позволяет определить компетентностный подход как метод анализа и совершенствования образовательных систем в плане их соответствия цели и задачам формирования компетентной личности.

Доказано, что компетенции/результаты образования зависят не столько от объема полученного знания, сколько от способности человека самостоятельно его пополнять, обоснованно ставить профессиональные задачи, вырабатывать критерии оценки и отбора наиболее эффективных путей их решения [5-8] и т.д. Поэтому применительно к проведению лекции компетентностный подход в современной высшей школе, по мнению авторов, обозначает следующее: педагогическая деятельность должна быть нацелена не на формирование у обучающихся отдельных компетенций или их групп, а на формирование целостной, компетентной, интеллектуально развитой и воспитанной личности. То есть формирование компетенций выступает уже не изелью, а средством.

Нельзя сказать, что традиционная вузовская лекция с преобладанием репродуктивных методов обучения в полном смысле слова сегодня неэффективна. Хорошую репродукцию в обучении никто и никогда не отменит, поскольку нельзя добиться от человека качественного выполнения познавательных действий, в том числе специально-предметных, если у него не сформированы 
элементарные репродуктивные навыки, такие как повторение, пересказ, действие по образцу, работа по плану и т.д. Кроме того, необходимо учитывать значение дисциплины и сложность изучаемой темы, время на освоение, ресурсные возможности вуза и т.д.

Тем не менее правила кредитной технологии выдвигают свои требования к организации и проведению лекции. Например, педагог должен грамотно управлять учебным временем, дисциплиной учебного труда, подбирать и распределять задания в условиях стандартизации образовательных программ, и все это - на фоне хронического недостатка аудиторного времени. Лектор, который долгое время использовал традиционный подход к обучению (монолог, рассказ, показ и т.д.), воспринимал пассивное слушание студентов как норму и главной свой задачей видел передачу фундаментальных знаний слушателям, должен изменить свою педагогическую позицию, модернизировать методику проведения лекции в соответствии c правилами кредитной технологии и компетентностного подхода.

Например, формируя теоретические и практические знания, лектор должен организовать поиск и анализ учебной информации самими обучающимися и при этом формировать в совместной работе со студентами не отдельное знание, а систему знаний, системное мышление, выявлять проблемы на стыке смежных наук, выдвигать гипотезы. Обучая навыкам анализа, нужно знакомить обучающихся с его видами, и в совместной работе со студентами определять наиболее ращиональные средства анализа для решения конкретной проблемы. Выбирая для занятия те или иные задания/вопросы, нужно четко определить значение конкретного знания/вопроса для решения той или иной проблемы, для достижения того или иного образовательного результа$m a$. В условиях непрекращающегося роста образовательных ресурсов в сети Интернет применять информационные технологии во время лекции также нужно по-новому, например не столько для обеспечения наглядности и доступности информации, сколько для развития u систематизащии знаний, мотивируя и активизируя процессы моделирования, абстрагирования, обобщения и т.д.

Иначе говоря, лектор в условиях кредитной технологии создает все условия и организует занятие так, чтобы в совместной работе со студентами максимально эффективно формировать систему научных знаний, развивать способности по самообразованию, воспитывать учебную самостоятельность. Методы, приемы, формы, средства и способы деятельности лектора должны служить одной цели - консультирование, организация и управление учебнопознавательной деятельностью в таком единственно возможном ее виде, чтобы обучаемые действительно стали обучающимися. На наш взгляд, именно в этом основное различие между традиционной вузовской лекцией и лекцией в условиях кредитной технологии и компетентностного подхода.

Для оценки эффективности лекции в условиях кредитной технологии необходим адекватный оценочный аппарат. С этой целью нами разработана система критериев и показателей оценки эффективности лекции. В течение учебного семестра проводился констатирующий эксперимент с участием 17 преподавателей. Посещались лекции, были организованы анкетирование и беседы с преподавателями, анализировались документы, типовые учебные программы, результаты контрольных срезов, творческих работ обучающихся.

Поскольку на результаты эксперимента влияло большое число факторов и параметров, был введен ряд ограничений. Были отобраны только дисциплины объемом не менее трех кредитов, с общим числом лекций - 15 , систематичностью 1 лекция в неделю. Лекции проводились для студентов только очного отделения, первого курса, весеннего семестра. Вводная (на первой неделе семестра) и итоговая (на 15-й неделе) лекции на констатирующем этапе эксперимента в учет не принимались по следующим причинам.

По определению, вводная лекция нацелена на формирование у студентов первоначального представления о содержании дисциплины, ее месте в учебном процессе и роли в будущей профессиональной деятельности [1-3, 
8]. Зачастую вводная лекция имеет популярный характер и представляет собой монолог преподавателя. На вводной лекции дается список литературы, методические рекомендации по разным видам занятий, обозначаются некоторые узловые моменты, на которые следует обратить особое внимание, и т.д. Также во время вводной лекции происходит знакомство с новой студенческой группой, проводится беседа, анкетирование студентов, сбор информации об учебных достижениях, интересах и склонностях, желании участвовать в научных конкурсах и соревнованиях. Что касается итоговой лекции, то она в основном завершает изучение дисциплины. Лектор подводит итоги, систематизирует знания, еще раз обращается к самым трудным моментам, показывает, как можно использовать полученные знания при изучении других дисциплин, обсуждает особенности экзамена. Поэтому посещение вводных и итоговых лекций не планировалось.

Лекции проводились только в современных аудиториях, оснащенных интерактивными и меловыми досками, проекторами, компьютерами, доступом в интернет. Число студентов в группе/ потоке - от 20 до 40. В качестве лекторов, принимающих участие в эксперименте, а также экспертов, наблюдающих за ходом лекционных занятий, выступили преподаватели с опытом работы в высшей школе не менее 15 лет, обладающие учеными степенями и званиями.

В качестве основных критериев оценки эффективности лекции выступили знание, компетенции и организация. Каждый из критериев раскрывался через систему показателей, оцениваемых по 100-балльной шкале. Показателями критерия «Знание» явились: передача фундаментальных и прикладных знаний; анализ фундаментальных и прикладных знаний; формирование основы для последующего усвоения материала. Критерий «Компетенции» раскрывался через универсальные и предметные компетенции. Наконец, в качестве показателей критерия «Организация» были определены: доминирующий тип освоения учебного материала; доминирующий тип анализа и применения знаний; работа студентов во время лек- ции; формирование у студентов различных способов учебной работы; роль демонстрационного материала, средств наглядности; подбор и применение демонстрационного материала, средств наглядности; управление вниманием студентов.

В результате экспериментальной работы по показателям критерия «Знание» и критерия «Компетенции» (универсальные компетенции) получены следующие данные: передача фундаментальных и прикладных знаний: $4 \%$ - высокий уровень, $31 \%$ - средний уровень, $55 \%$ - низкий уровень; анализ фундаментальных и прикладных знаний: высокий уровень не выявлен, $19 \%$ - средний уровень, $81 \%$ - низкий уровень.

Особое значение имело для нас формирование показателя «Основа для последующего усвоения материала». В ходе эксперимента получены следующие результаты: структура научного знания не построена, связи изучаемой темы с другими темами/разделами дисциплины и междисциплинарные связи не найдены - $60 \%$; присутствуют редкие попытки построения структуры научного знания, лектор (без участия студентов) демонстрирует 1-2 примера связи изучаемой темы с другими темами/разделами дисциплины - 37\%; в совместной работе со студентами строится структура научного знания, находятся и фиксируются связи изучаемой темы с другими темами/разделами дисциплины и междисциплинарные связи $-3 \%$.

По показателям критериев «Компетенции» (предметные компетенции) и «Организация» по итогам экспериментальной работы получены следующие данные.

Доминирующий тип освоения учебного материала: преобладает монолог преподавателя - 87\%; преобладает учебный диалог - $13 \%$.

Доминирующий тип анализа и применения знаний: преобладает показ, демонстрация, тренировка - 79\%; преобладает решение проблемных ситуаций $-11 \%$.

Работа студента во время лекции: студенты в основном пассивны - $71 \%$; студенты иногда проявляют активность, отвечают на вопросы лектора - 27\%; 
студенты в основном работают в парах и группах, активно обсуждают проблемные ситуации, дискутируют и спорят друг с другом $-2 \%$.

Формирование у студентов различных способов учебной работы: способы учебной работы у студентов не формируются, форма работы студентов во время лекции одна и та же (слушание, чтение, конспектирование лекции) - $63 \%$; встречаются отдельные попытки формирования у студентов способов учебной работы - $36 \%$; лектор постоянно и целенаправленно предлагает студентам освоить новые способы учебной работы - 0 .

Роль демонстрационного материала, средств наглядности: демонстрационный материал, средства наглядности играют подчиненную роль, а не подменяют содержание лекции - $53 \%$; демонстрационный материал, средства наглядности играют определяющую роль; если, например, интерактивная доска, проектор или компьютер перестают по какой-то причине работать, ход лекции нарушается, студенты теряют интерес к изучаемому материалу $-47 \%$.

Подбор и применение демонстрационного материала, средств наглядности: демонстрационный материал, средства наглядности высокого качества, тщательно отобраны, применяются дозированно, их использование помогает понять какой-то сложный, узловой момент темы - $25 \%$; демонстрационный материал, средства наглядности применяются на протяжении всего занятия, даже тогда, когда в этом нет необходимости $-75 \%$.

Управление вниманием студентов: повышенное внимание и мыслительное напряжение студентов время от времени сопровождаются разрядкой - 55\%; в основном внимание и мыслительное напряжение не сопровождаются разрядкой, к концу лекции студентам все труднее удерживать внимание - $34 \%$; студенты в основном не проявляют внимания к лекции, постоянно отвлекаются - $11 \%$.

\section{Выводы}

По результатам исследования сделано заключение о том, что традиционная форма организации и проведения лекции, с преобладанием монолога и репродуктивных методов обучения, в условиях кредитной технологии не позволяет получить ожидаемые в рамках компетентностного подхода образовательные результаты. На следующем этапе исследования предстоит организовать ряд научно-методических семинаров, мастерклассов, открытых занятий с целью подготовки преподавателей к организации и проведению лекций, отвечающих требованиям компетентностного подхода и правилам кредитной технологии обучения.

\section{Список литературы}

1. Елбаев Ю.А. Обучение и воспитание в высшей школе. - М.: Перо, 2017. - 276 с.

2. Скибицкий Э.Г. Дидактика высшей школы. Новосибирск: НГПУ, 2017. - 127 с.

3. Фетюхин М.И. Психолого-педагогические основы учебной лекции. - Волгоград: Изд-во ВГУ, 1997. - 179 c.

4. Ponomarenko Y., Kenzhebekova R., Larchenkova L. et at. Pedagogical research methods of training in higher educational establishments: A comparative analysis // International Electronic Journal of Mathematics Education. - Vol. 11. - Is. 9. - 2016. - P. 3221-3232.

5. Адырбекова Г.М., Пономаренко Е.В. Влияние компетентностного подхода на уровень подготовки технических специалистов в высших учебных заведениях // Известия НАН РК, серия «Общественные и гуманитарные науки». - 2016. - № 3. - С. 148-151.

6. Клушина Н.П. Теоретические аспекты и практическая реализация компетентностного подхода в высшем образовании: монография. - Ставрополь: Альфа Принт, 2014 - 263 с.

7. Петрова Т.А. Проблемы реализации компетентностного подхода при обучении студентов вуза: монография. - Краснодар: КСЭИ, 2016. - 97 с.

8. Тасыбаева Ш.Б., Арыстанбаев К.Е., Хамитова Б.М. Объединение традиционных форм обучения и E-LEARNING в развитии образования/ Труды 3 форума педагогов-новаторов «Инновационные информационно-педагогические технологии в образовании». - Шымкент: ЮКГУ им. М. Ауэзова, 2012. С. $276-278$. 